Original Research Article

\title{
Indigenous methods for assessment of important aspects in undergraduates on pharmacology and therapeutics: a preliminary study
}

\author{
Naresh D. Balani, Namrata U. Mahadkar*, Ritesh C. Sonawane
}

Department of Pharmacology, GMC, Akola, Maharashtra, India

Received: 30 June 2017 Accepted: 24 July 2017

\section{*Correspondence to:}

Dr. Namrata U. Mahadkar, Email: namratamahadkar@ gmail.com

Copyright: () the author(s), publisher and licensee Medip Academy. This is an openaccess article distributed under the terms of the Creative Commons Attribution NonCommercial License, which permits unrestricted noncommercial use, distribution, and reproduction in any medium, provided the original work is properly cited.

\begin{abstract}
Background: In pharmacology and therapeutics tutorial in current times is being disliked by most undergraduates. On the other hand, the important exercises related to analytical skill development, problem based exercise, rational use of medicine and individualized drug therapy need to be emphasize more in UG teaching and learning techniques.

Methods: In the form of active learning we have framed CME pattern of conducting some important exercises including four above mentioned to facilitate the ability to think, feel or do the task which may be acceptable to the students better than or equivalent to tutorials.

Results: We observed that 2 out of 8 willing participants scored higher than others in CME activity as well as terminal exams the other 2 scored borderline higher in CME activity than their score in terminal exams. Another 4 scored better in the terminal examinations as compared to CME activity. 4 out of 8 i.e. $50 \%$ participants have shown acceptability as well as better performance in these exercises.

Conclusions: All of these exercises are not in the curriculum/syllabus and there is no incentive of internal assessment on these. If these exercises are made mandatory, as it is the need of the hour, these can benefit the learner possibly by the way of change in their cognitive structure, keeping tutorials intact or removing them from syllabus.
\end{abstract}

Keywords: Individualized therapy, Learning, Methodology, Rational use

\section{INTRODUCTION}

Tutorials is one of the methods of bilateral communication in undergraduates training mentioned in their curriculum in syllabus, wherein teacher ask short answer questions on specified (pre informed topic) and students are expected to answer, this method has advantage of preparing student for immediate recall, viva voce answers, along with possibility of change in their cognitive structure. However, it is becoming less and less popular among students. It has been observed that $80 \%$ and above students do not like this type of learning probably because it needs the preinformed topic to be prepared irrespective of their liking, and also fear of wrong answers and mistakes being revealed to other students of batch. Ability to think, feel and to do the task can reflect the change in the cognitive structure of learner indirectly. ${ }^{1}$ There is need to design the technique of learning this should be interesting without above said drawbacks to reflect the active learning process. Modification in behavior as a result of exercise practice and experience has been defined as learning. ${ }^{2}$ Many basic facts of medical sciences had to be presented as per theory of meaningful verbal learning. ${ }^{3}$ Strategy to solve a problem is deduced by learner through exploration of relationship between received elements. ${ }^{4}$ Linking surface and deep learning can be made possible by this way. ${ }^{4}$ There is growing dissatisfaction over quality of learning by traditional way in medical schools..$^{5}$ Moreover in many 
instances medical teachers have joined profession with minimum love for teaching. ${ }^{6}$ Less specificity and less adequacy of knowledge to be gained by learner have been reported in an attitudinal study. ${ }^{7}$ At some centers in pharmacology subject there is no experimental exercise to be done by students themselves which deprives them from development of psychomotor domain on the other hand internal assessment is done purely on basis of performance of student in term ending exam due to which there will be lack of skill development in students. There is need to introduce exercises to develop ability to solve a problem situation, to choose best priority out of multiple options in unprecedented, their ability to participate in group discussion, ability to undertake research project. In view of development of above said abilities we have framed the group of exercises under the CME heading which are needed to be undertaken along with the present examination system for undergraduates receiving training in pharmacology and therapeutics.

\section{METHODS}

10 Undergraduate students out of 25 of 2012 batch underwent learning on above mentioned exercises for development of interests in the subject and for development of skill required for research project assessment on these aspects and formatting were done by two different teachers. The total scores in the group of exercises were compared with that of scores in terminal examination to establish whether there is any link amongst these two performances. Out of maximum total 130 on CME exercises the performance scores were recorded in tabulated manner as shown in table of observations. The ethical clearance from institutional ethics committee was not necessary as most exercises are curriculum and academic based, without interventional and invasive technique using paper pencil only. As it is the study on the performance on students on CME and terminal exams without comparison, statistical test and analysis is not required. In current scenario the following skills are needed to be developed using exercises in under graduate along with the development of interest in learning.

\section{ASD (Analytic skill development)}

ASD in present scenario is grossly lacking because experimental work by students themselves is not in curriculum. using the animal experimental software, actual experimental graphs, identification of unknown drug exercise can be carried out to develop analytical skill. This development of skill will be helpful to them while working as clinician or academician in future

\section{Class work}

Class work the short answer question exercises can be framed out and given to students in the class before and or after the delivery of text matter in lectures. Similarly a separate work book can be introduced which has to be filled in by work during the class timings.

\section{FB-task (Fish bowl)}

FB- task (Fish bowl) exercise by giving them a topic from their curriculum and asking them to discuss and put their views on it. From this type of exercise, we can come to know not only their opinions but also some innovative thoughts which otherwise is not possible in traditional type of teaching.

\section{Homework}

Homework exercise by giving them a topic on which they will prepare a short note based information. The topic herein is so selected that requires linking of one aspect with that of other aspects. Thus the complete and proper linking ability can be assessed in this manner e.g. linking of pharmacological actions with therapeutic uses and excess dose causing adverse reactions. Also the multi receptor action profile of the drug can be linked with its main use, subsidiary use, side effects and adverse reactions.

\section{IDT (Individualized drug therapy)}

IDT is the important aspect in current times wherein there are multiple drugs available for treatment of one particular disease/disorder. Based on patient, comorbidity and drug factors, correct selection of drug from available options can be developed using this exercise e.g. selection of antihypertensive drug, antidiabetic drug etc. We have framed in our studies the exercises to select a drug for patient of hypertension with comorbidities (like bronchial asthma, diabetes mellitus, cardiac failure etc.)

\section{PBL (Problem based learning)}

PBL is also an important aspect in pharmacology therapeutics for which undergraduate should be sufficiently trained this incorporates inclusion of simple type of therapeutic problems first in exercise 1 and then raising the difficulty level in the form of criticize correct rewrite based on possible drug interaction in therapeutics and toxicology (PBL1 PBL 2).

\section{PF (Priority fixation)}

PF exercise will make them sharper in selecting the most proper option as priority in problematic situation. The problematic situation exercise can be designed from any of the medical faculty related topic

\section{RMO (Research methodology orientation)}

RMO and research project related exercise (protocol design, clearance from ethics committee, ICMR projects etc.) related learning in the form of orientation first and then the task on other aspects is assessed for completeness and correctness. This serves as the ultimate exercise which includes most of the other type of exercises mentioned earlier. Development of research skill is the ultimate aim. 


\section{RUM (Rational use of medicine)}

Rational use of medicine is very important aspect in medicine. The knowledge and active participation in selecting a correct drug, using it in the correct dose in the most needy person at the minimum cost. This is another important exercise which is aimed at development of therapeutic skill e.g. rationality of use of antimicrobial of different age group and different diseased states in patients of typhoid. The ethical clearance from institutional ethics committee was not necessary as most exercises were academic based without interventional or invasive technique.

The score of each student was tabulated to calculate their scores in Table 1 and Table 2 separately of CME exercises and terminal examinations. First column includes different heads of activities. second column shows maximum marks and third column shows best scores in Table 2 .
The scores of each student thus tabulated was further analysed (refer observation and results). We ranked the participants with their performance scores and tried to find out any correlation amongst the performance in terminal exam and CME exercises.

\section{RESULTS}

Two students out of 10 (roll no 1211 - highest scorer and 1291-who emerged equally good scorer despite non participation in few exercises). 3 students attended research methodology orientation speech however none of them could submit research protocol because of their final examination.

Another 4 scored better in the terminal examinations as compared to CME activity. Whereas 2 did not participate in most exercise of activity (1213 and 1293 in Table 2) and were dropped out. The range of scores in terminal exams (out of 266) was 141.5 to 180 . whereas the range of scores in CME (max 130) was 9.5 to 72.7 .

Table 1: The scores of participants in internal assessment exams $1^{\text {st }}$ term, $2^{\text {nd }}$ term and prelim examination.

\begin{tabular}{|llllllllllll|}
\hline Exams & Max & $\mathbf{1 2 0 6}$ & $\mathbf{1 2 1 1}$ & $\mathbf{1 2 1 3}$ & $\mathbf{1 2 1 4}$ & $\mathbf{1 2 2 3}$ & $\mathbf{1 2 6 4}$ & $\mathbf{1 2 9 1}$ & $\mathbf{1 2 9 3}$ & $\mathbf{1 2 0 9}$ & $\mathbf{1 2 2 1}$ \\
\hline Theory & 50 & 34 & 38 & 33.5 & 34 & 32.5 & 26 & 38.5 & 24 & 38.5 & 32.5 \\
\hline Pract(-)viva & 30 & 14 & 16.5 & 19 & 15 & 17 & 16.5 & 19 & 16 & 16.5 & 14 \\
\hline Theory & 50 & 27 & 33 & 30.5 & 34.5 & 32.5 & 27 & 34 & 23 & 36 & 32.5 \\
\hline Pract(-)viva & 30 & 19.5 & 21.5 & 18.5 & 18 & 19.5 & 16.5 & 21.5 & 20.5 & 21.5 & 19.5 \\
\hline Theory-I & 40 & 22 & 27.5 & 24.5 & 27.5 & 25 & 20 & 32 & 27.5 & 27.5 & 23 \\
\hline Theory-II & 40 & 17.5 & 23 & 23 & 18 & 18.5 & 20.5 & 20.5 & 18 & 23 & 18.5 \\
\hline Pract(-)viva & 26 & 13.5 & 13 & 15.5 & 14 & 13 & 15.5 & 14.5 & 12.5 & 15 & 13 \\
\hline Total & 266 & 147.5 & 172.5 & 164.5 & 161 & 158 & 142 & 180 & 141.5 & 178 & 153 \\
\hline & $\%$ & 55.45 & 64.66 & 61.84 & 60.52 & 59.39 & 53.38 & 67.66 & 53.19 & 67 & 57.6 \\
\hline
\end{tabular}

Table 2: The scores of the participants in CME related topics exercises.

\begin{tabular}{|c|c|c|c|c|c|c|c|c|c|c|c|c|}
\hline Heads & MAX & BEST & 1206 & 1209 & 1211 & 1213 & 1214 & 1221 & 1223 & 1264 & 1291 & 1293 \\
\hline ASD & 12 & 10 & 6.2 & 4.5 & 6.5 & 0 & 0 & 0 & 0 & 6 & 10 & 0 \\
\hline Class-work & 26 & 18.5 & 8 & 17.5 & 13.5 & 0 & 0 & 0 & 0 & 10.5 & 18.5 & 3 \\
\hline Fish bowl & 2 & 2 & 2 & 2 & 2 & 0 & 2 & 2 & 2 & 0 & 0 & 0 \\
\hline FB task & 5 & 5 & 4 & 2 & 5 & 0 & 2 & 4 & 5 & 0 & 0 & 0 \\
\hline Home work & 30 & 21 & 0 & 0 & 7.5 & 0 & 6 & 0 & 0 & 15 & 21 & 0 \\
\hline IDT & 5 & 4 & 3.5 & 0 & 4 & 0 & 0 & 0 & 0 & 1.5 & 0 & 0 \\
\hline PBL-1 & 14 & 12 & 11 & 0 & 12 & 0 & 0 & 0 & 0 & 11 & 8.7 & 0 \\
\hline PBL-2 & 16 & 7.5 & 7.5 & 0 & 7.5 & 0 & 0 & 0 & 0 & 7.5 & 4 & 0 \\
\hline $\mathrm{PF}$ & 2 & 2 & 2 & 0 & 2 & 0 & 0 & 5.2 & 0 & 2 & 0 & 0 \\
\hline PF task & 11 & 5.5 & 5 & 3.5 & 4 & 0 & 5 & 0 & 2.5 & 3 & 5.5 & 0 \\
\hline RMO & 2 & 2 & 2 & 0 & 2 & 0 & 0 & 0 & 0 & 2 & 0 & 0 \\
\hline RUM & 5 & 5 & 0 & 0 & 5 & 0 & 0 & 0 & 0 & 5 & 5 & 0 \\
\hline
\end{tabular}

ASD - Analytical skill development

FB task - fish bowl task

IDT - individualised drug therapy: Anti hypertensive drug selection

PBL 1 Problem based learning 1

PBL 2 Problem based learning 2

PF-Priority fixation

PF Task - Priority fixation task

RMO - Research methodology orientation

RMU-Rational use of medicine 


\section{DISCUSSION}

Scoring of $50 \%$ and above by all the included students is due to condition of passing compulsory internal assessment i.e. minimum $35 \%$ in term exams for eligibility to appear in final exams.

$25 \%$ (2 out of 8 ) subjects showed their interest in CME activities and also enjoyed the active learning. About remaining $75 \%$ ( 6 out of 8 ) their interest can be increased by giving due weightage to the scores, similar to internal assessment. Analytical skill development exercises, problem based learning, individualized drug therapy and rational use of medicine exercise are best favorite requirements for UG learning. Classwork and homework are also known to improve the cognitive structure whereas research methodology orientation is going to promote them to undertake fact finding tasks in their academics for future.

The active learning in pharmacology and therapeutics can be in this manner introduced for the betterment of medical undergraduates learning. As we know that therapeutics is backbone of health care being second important after final diagnosis. Brings et al has already defined instructions, which provide controlled environment to mould learning in pre decided way. ${ }^{8}$ The complex task should be broken down into smaller simpler task in teaching and learning process. ${ }^{9}$ Many medical schools use problem based learning as a deep approach method as full time curriculum or a traditional curriculum. ${ }^{10,13}$ In many institutions only therapeutic problem based exercises are covered in traditional curriculum in the form of practical exercise in final exam. As in our study $75 \%$ of students could not perform in CME exercises parallel to their performance in terminal exams, there is need to include these exercises in traditional curriculum. However, at present there is no incentive in the form of internal assessment to make students to participate. ${ }^{2}$ Larger teaching staff required for such types of inclusion of exercises so that small batches can be prepared. ${ }^{3}$ There is still possibility of some students may still be not interested as the subject is nonclinical one. ${ }^{8}$

\section{ACKNOWLEDGEMENTS}

Authors would like to thank to students of 2012 batch who cooperated us by willing participation in the study.

Funding: No funding sources Conflict of interest: None declared

Ethical approval: Not required

\section{REFERENCES}

1. Dave PM. Hierarchy in cognitive learning- an experiential project for advance curriculum Model. Regional workshop of medical Education. Mysore, India - $1^{\text {st }}$ Ed: 1976. Trends Med Edu. BORICP05.doc - 1 chapter 5 .

2. Such MV, Thomas AG, Singh T. What is learning: Active learning in traditional medical schedulelessons from theories of learning. Trends Med Edu. 1997;34:1015-19.

3. Ausubel DP, Nevack JD. Education psychology-a cognitive view. Trends Med Edu. Holt, Rinehart and Winston, 1968 section 3 cognitive factors in learning. Available at: http://www.thenhier.ca/en/node/464.

4. Natu MV, Thomas AG, Singh T. Cognitive theories of learning: Active learning in traditional medical schools- lessons from theories of learning. Trends Med Edu. 1995;2:16-17.

5. Medico friend cricle. Medical education re-examined. Pune $1^{\text {st }}$ Ed. 1991. Trends Med Edu. 1997;2:3-6.

6. Narayan R. Medical education re-examined. 1 ed. Pune: Medico friend circle, 1992. JIMA. 1997;95(8):454-55.

7. Singh T, Natu MV, Thomas AG. What do medical teachers feel regarding teaching - An attitudinal study. JIMA. 1997;95(8):54-55.

8. Brings LJ. An overview of international system design. Tallahassee, Florida state university- 1st Ed:1975. Trends Med Edu. 1995;2:3-6.

9. Natu MV, Thomas AG, Singh T. Continuous Internal Assessment- Concept and application in medical education. Trends Med Edu. 1995;2:16-7.

10. Jayawickramarajah PT. Curricular reforms in medical schools. Bahrain Med Bull. 1986;8:47-53.

11. Vernon TA, Blake RL. Does problem-based learning work? A meta-analysis of evaluative research. Acad Med. 1993;68:550-63.

12. Des Marchais JE. A student-centred, problem-based curriculum: 5 years' experience Can Med Assoc J. 1993; 148:1567-72.

13. Colliver JA. Effectiveness of problem-based learning curricula: Research and theory Acad Med. 2000;75:259-66.

Cite this article as: Balani ND, Mahadkar NU, Sonawane RC. Indigenous methods for assessment of important aspects in undergraduates on pharmacology and therapeutics: a preliminary study. Int J Basic Clin Pharmacol 2017;6:2210-3. 